\title{
Effects of diets containing sunflower oil and fish oil on lipid metabolism and fatty acid flow to the duodenum of beef steers
}

\author{
M.R.F. Lee ${ }^{1,3}$, J.K.S. Tweed ${ }^{1}$, A.P. Moloney ${ }^{2}$ and N.D. Scollan ${ }^{1}$ \\ ${ }^{1}$ Institute of Grassland and Environmental Research \\ Plas Gogerddan, Aberystwyth, UK \\ ${ }^{2}$ Teagasc, Grange Research Centre \\ $C^{o}$ Meath, Eire
}

\begin{abstract}
Duodenal fistulated steers were offered grass silage at $14 \mathrm{~g} / \mathrm{kg}$ liveweight and one of three concentrates at a ratio of 60:40 (forage:concentrate on a dry matter basis): FISH0, FISH1 or FISH2 designed to be iso-lipid and to provide the same amount of sunflower oil but increasing amounts of fish oil: 0,1 and $4 \%$, respectively. Fatty acid intakes and duodenal flows were examined to determine the effects of fish oil on polyunsaturated fatty acid (PUFA) metabolism. Fish oil significantly increased the flow of long chain PUFA, conjugated linoleic acid and trans vaccenic acid to the duodenum and decreased the flow of stearic acid. Biohydrogenation of linoleic and linolenic acids was not affected by fish oil inclusion.
\end{abstract}

KEY WORDS: fish oil, rumen metabolism, trans vaccenic acid, conjugated linoleic acid, fatty acids

\section{INTRODUCTION}

Clinical research has shown that the intake of polyunsaturated fatty acids (PUFA) and in particular long chain PUFA such as C20:5n-3 and C22:6n-3 found in fish oil are beneficial to human health (Tapiero et al., 2002). Previous studies have shown that fish oil inclusion in the diet of ruminants has increased the concentration of long chain PUFA in milk (Shingfield et al., 2003) and muscle (Scollan et al., 2001a). Fish oil also significantly increased the post-ruminal flow of trans vaccenic acid (TVA), an intermediate in the biohydrogenation of linoleic and linolenic acid (Scollan et al., 2001b; Shingfield et al., 2003). This may have been responsible for the observed increase in the concentration of conjugated linoleic acid (CLA) in milk through the

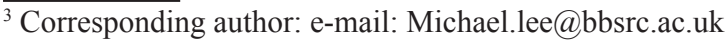


bioconversion of TVA to cis 9 trans 11 CLA in the mammary gland (Shingfield et al., 2003). This study was designed to report the effect of graded levels of fish oil on the flow of long chain PUFA and biohydrogenation intermediates such as TVA and CLA, when steers were offered a flat rate of linoleic acid, supplied from sunflower oil. It was hoped this would create a greater understanding of the effect of fish oil in the biohydrogenation of C18 PUFA.

\section{MATERIAL AND METHODS}

\section{Animals and experimental design}

Six Hereford x Friesian steers (about $410 \mathrm{~kg}$ ), prepared with rumen and duodenal cannulae were offered a first cut perennial ryegrass silage plus one of three concentrates: FISH0, FISH1 or FISH2 (Table 1). The total daily feed allowance was $14 \mathrm{~g} \mathrm{DM} / \mathrm{kg}$ liveweight (about 90\% ad libitum) with a forage: concentrate ratio of 60:40 (DM basis). The experiment design was a Latin square consisting of 3-periods with two animals per treatment. Each $21 \mathrm{~d}$ period consisted of $14 \mathrm{~d}$ adaptation to the diet and $7 \mathrm{~d}$ for digesta collection. Animals received their daily forage allocation at 09.00 and their daily concentrate allocation in 2 equal meals at 09.00 and 15.00. Digesta flow at the duodenum was estimated using a dual-phase marker system with ytterbium acetate and chromium EDTA as the particulate and liquid phase markers, respectively (Faichney, 1975).

Table 1. Formulation of the experimental concentrates

\begin{tabular}{lccc}
\hline Ingredient, kg/tonne fresh & FISH0 & FISH1 & FISH2 \\
\hline Barley & 345 & 345 & 345 \\
Sugar beet pulp & 360 & 360 & 360 \\
Soyabean meal & 140 & 140 & 140 \\
Molasses & 10 & 10 & 10 \\
Min/vit & 25 & 25 & 25 \\
Sunflower oil & 80 & 80 & 80 \\
Fish oil (Herring (Clupeidae spp.) offal) ${ }^{1}$ & 0 & 10 & 40 \\
Lard & 40 & 30 & 0 \\
Total & 1000 & 1000 & 1000 \\
\hline
\end{tabular}

1200 ppm ethoxyquin added as an anti-oxidant

\section{Chemical and statistical analysis}

Chemical and fatty acid compositions of the silages and digesta were determined as described by Lee et al. (2003). Digesta flows were calculated after mathematical reconstitution of true digesta as described by Faichney (1975). Biohydrogenation of C18 PUFA was assessed as the difference between daily intake and duodenal flow (g/day). Data were subjected to ANOVA (Genstat 7 (C, 2004) with diet as the treatment effect and blocking according to period + animal. 


\section{RESULTS}

Dry matter and major fatty acid intake and duodenal flow are given in Table 2. There were no significant differences in nutrient and total fatty acid intake and duodenal flow. Increasing the concentration of fish oil in the diet significantly increased the intake and duodenal flow of long chain PUFA. It also increased the flow of TVA and CLA, but not the isomer cis 9 trans 11, and decreased the flow of stearic acid. Biohydrogenation of linoleic and linolenic acid were not significantly different across diets, averaging 90.8 and $91.8 \%$, respectively.

Table 2. Dry matter and major fatty acid intake and duodenal flow

\begin{tabular}{|c|c|c|c|c|c|}
\hline & FISH0 & FISH1 & FISH2 & S.e.d. & $\mathrm{P}$ \\
\hline \multicolumn{6}{|l|}{ Intake, $g / d$} \\
\hline dry matter, $\mathrm{kg} / \mathrm{d}$ & 7.55 & 7.55 & 7.45 & 0.171 & NS \\
\hline C16:0 palmitic & 67.2 & 66.1 & 58.7 & 0.81 & 0.001 \\
\hline C18:0 stearic & 25.1 & 22.7 & 13.8 & 0.48 & 0.001 \\
\hline C18:1n-9 oleic & 88.7 & 90.2 & 76.1 & 5.71 & 0.001 \\
\hline C18:2n-6 linoleic & 167.6 & 172.3 & 170.6 & 8.18 & NS \\
\hline C18:3n-3 linolenic & 48.0 & 48.6 & 47.7 & 1.47 & NS \\
\hline C20:5n-3 eicosapentaenoic & 0.170 & 1.34 & 5.99 & 0.155 & 0.001 \\
\hline C22:5n-3 docosapentaenoic & - & 0.275 & 0.919 & 0.0179 & 0.001 \\
\hline C22:6n-3 docosahexanoic & 0.063 & 1.99 & 8.66 & 0.142 & 0.001 \\
\hline total fatty acids & 419.8 & 433.1 & 427.9 & 6.50 & NS \\
\hline \multicolumn{6}{|l|}{ Duodenal flow, $g / d$} \\
\hline dry matter, kg/d & 4.40 & 4.50 & 4.38 & 0.241 & NS \\
\hline C16:0 Palmitic & 87.1 & 89.5 & 80.3 & 3.95 & NS \\
\hline C18:0 Stearic & 275.4 & 259.1 & 169.8 & 10.49 & 0.001 \\
\hline C18:1 trans 11 & 50.6 & 74.2 & 83.2 & 9.46 & 0.022 \\
\hline total trans $\mathrm{C} 18: 1$ & 68.2 & 93.9 & 117.0 & 7.57 & 0.001 \\
\hline total cis $\mathrm{C} 18: 1$ & 40.6 & 41.3 & 42.1 & 2.54 & NS \\
\hline CLA cis 9 trans 11 & 0.930 & 1.51 & 1.09 & 0.2441 & NS \\
\hline total CLA & 2.65 & 3.89 & 6.59 & 0.398 & 0.001 \\
\hline C18:2n-6 linoleic & 15.8 & 17.5 & 13.5 & 1.01 & 0.012 \\
\hline C18:3n-3 linolenic & 4.07 & 4.06 & 3.65 & 0.287 & NS \\
\hline C20:5n-3 eicosapentaenoic & 0.47 & 0.68 & 1.24 & 0.068 & 0.001 \\
\hline C22:5n-3 docosapentaenoic & 0.30 & 0.34 & 0.57 & 0.063 & 0.006 \\
\hline C22:6n-3 docosahexanoic & 0.41 & 0.53 & 1.21 & 0.082 & 0.001 \\
\hline total fatty acids & 543.7 & 568.3 & 507.6 & 26.94 & NS \\
\hline
\end{tabular}

\section{DISCUSSION}

All three diets in the present study resulted in net synthesis of fatty acids across the rumen as previously reported by Scollan et al. (2001b) when feeding a fish oil 
supplement, and this maybe due to endogenous lipid or microbial synthesis. Fish oil had no effect on the extent of biohydrogenation of either linoleic or linolenic acid, but significantly increased the flow of the intermediate products TVA and total CLA and significantly reduced the flow of the end product stearic acid. However, there was no significant difference in the flow of cis 9 trans 11 CLA, the product of the initial isomerisation of linoleic acid in biohydrogenation, in these diets and so the effect of fish oil appeared to be an inhibition to the final reduction of TVA into stearic acid. Wallace et al. (2004) have identified two species of ruminal bacteria responsible for the biohydrogenation of both linoleic and linolenic acid due to their extreme sensitivity to PUFA, namely Butyrivibrio fibrisolvens and Fusocillus spp. These bacteria in conjunction but not in isolation can hydrogenate linoleic and linolenic acid to stearic acid. B. fibrisolvens hydrogenates the PUFA to cis 9 trans 11 CLA and TVA and Fusocillus completes the hydrogenation of TVA to stearic acid. It may be that the long chain PUFA in fish oil inhibits Fusocillus resulting in a significant elevation in TVA and consequently an increase in milk CLA through TVAs bio-conversion in the mammary gland (Shingfield et al., 2003).

\section{REFERENCES}

Faichney G.J., 1975. The use of markers to partition digestion within the gastro-intestinal tract of ruminants. In: I.W. McDonald, A.C.I. Warner (Editors). Digestion and Metabolism in the Ruminant. University of New England, Armidale, pp. 277-291

Lee M.R.F, Harris L.J., Dewhurst R.J., Merry R.J., Scollan N.D., 2003. The effect of clover silages on long chain fatty acid rumen transformations and digestion in beef steers. Anim. Sci. 76, 491501

Scollan N.D., Choi N.J., Kurt E., Fisher A.V., Enser M., Wood J.D., 2001a. Manipulating the fatty acid composition of muscle and adipose tissue in beef cattle. Brit. J. Nut. 85, 115-124

Scollan N.D., Dhanoa M.S., Choi N.J., Maeng W.J., Enser M., Wood J.D., 2001b. Biohydrogenation and digestion of long chain fatty acids in steers fed on different sources of lipid. J. Agr. Sci. 136, 345-355

Shingfield K.J., Ahvenjarvi S., Toivonen V., Arola A., Nurmela K.V.V., Huhtanan P., Griinair J.M., 2003. Effect of dietary fish oil on biohydrogenation of fatty acid and milk fatty acid content in cows. Anim. Sci. 77, 165-179

Tapiero H., Nguyen Ba G., Couvreur P., Tew K.D., 2002. Polyunsaturated fatty acid (PUFA) and eicosanoids in human health and pathologies. Biomed. Pharmacotherapy 56, 215-222

Wallace R.J., Walker N.D., Richardson A.J., Chaudhary L.C., Koppova I., McEwan N.R., McKain N., King T.P., Newbold C.J., 2004. Re-isolation, identification, and propertied of 'Fusocillus', the only species of ruminal bacteria known to convert linoleic acid to stearic acid. Appl. Environ Microbiol. 70 